\title{
A prospective study of the substance use and mental health outcomes of young adult former and current cannabis users
}

Edmund Silins ${ }^{1}$, Wendy Swift ${ }^{1}$, Tim Slade ${ }^{1}$, Barbara Toson ${ }^{1}$, Bryan Rodgers ${ }^{2}$, Delyse M. Hutchinson $1,2,3,4,5$

${ }^{1}$ National Drug and Alcohol Research Centre, UNSW Australia, Sydney, Australia

${ }^{2}$ Australian Demographic and Social Research Institute, Australian National University, Canberra, Australia

${ }^{3}$ Centre for Social and Early Emotional Development, School of Psychology, Deakin University, Geelong, Australia

${ }^{4}$ Centre for Adolescent Health, Murdoch Childrens Research Institute, Royal Children's Hospital, Melbourne, Australia

${ }^{5}$ Department of Paediatrics, University of Melbourne, Melbourne, Australia

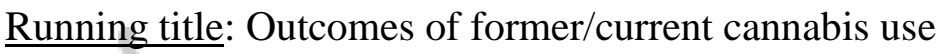

Edmund Silins PhD, MPH (Hons), Bnurs, Research Fellow, Wendy Swift BA (Hons), MPH, $\mathrm{PhD}$, Senior Lecturer, Tim Slade PhD, BSc (Psychol) Hons, Associate Professor, Barbara Toson BStatEc, Biostatistician, Bryan Rodgers BA (Hons), MA, MSc, PhD, Professor, Delyse M. Hutchinson BA/BSc, PhD/MClinPsych, Senior Lecturer. Correspondence to Edmund Silins, National Drug and Alcohol Research Centre, UNSW Australia, Sydney, NSW, Australia, 2052. Ph: 6129385 0141; Fax: 6129385 0222; Email:

e.silins@unsw.edu.au

This is the author manuscript accepted for publication and has undergone full peer review but has not been through the copyediting, typesetting, pagination and proofreading process, which may lead to differences between this version and the Version of Record. Please cite this article as doi: $10.1111 /$ dar.12512

This article is protected by copyright. All rights reserved. 


\section{ABSTRACT}

Introduction and Aims: The extent to which young adult former cannabis users fare better than infrequent users is unclear. We investigated the association between cannabis use status at age 23 and substance use and mental health outcomes at age 27. Design and Methods: Data were from the 20+ year cohort of the PATH Through Life Study. Lifetime cannabis users $(\mathrm{N}=1410)$ at age 23 were classified as former/occasional/regular users. Multivariable logistic regression was used to estimate the association between cannabis use status at age 23 and six outcomes assessed at age 27. Results: Compared to occasional cannabis users: (i) former users had odds of subsequent tobacco use (odds ratio $[\mathrm{OR}]=0.67,95 \%$ confidence interval [CI] 0.52-0.85), illicit drug use (cannabis, OR=0.22, 95\% CI 0.17-0.28; other illicit drugs, $\mathrm{OR}=0.29,95 \%$ CI 0.22-0.39) and mental health impairment $(\mathrm{OR}=0.71,95 \%$ CI 0.55 0.92) that were 29-78\% lower; and (ii) regular users had odds of subsequent frequent alcohol use $(\mathrm{OR}=2.34,95 \% \mathrm{CI}$ 0.67-1.34), tobacco use (OR=3.67, 95\% CI 2.54-5.30), cannabis use (OR=11.73, 95\% CI 6.81-20.21) and dependence symptoms (OR=12.60, 95\% CI 8.38-18.94), and other illicit drug use (OR=2.95, 95\% CI 2.07-4.21) that were 2-13 times greater. Associations attenuated after covariate adjustment and most remained significant.

Discussion and Conclusions: Clear associations exist between cannabis use status in young adulthood and subsequent mental health and substance use. While early intervention remains important to prevent regular cannabis use and the associated harms, experimentation with cannabis use in the years leading into young adulthood may not necessarily determine an immutable pathway to mental health problems and illicit substance use. 
Keywords: Cannabis; young adult; substance abuse; mental health

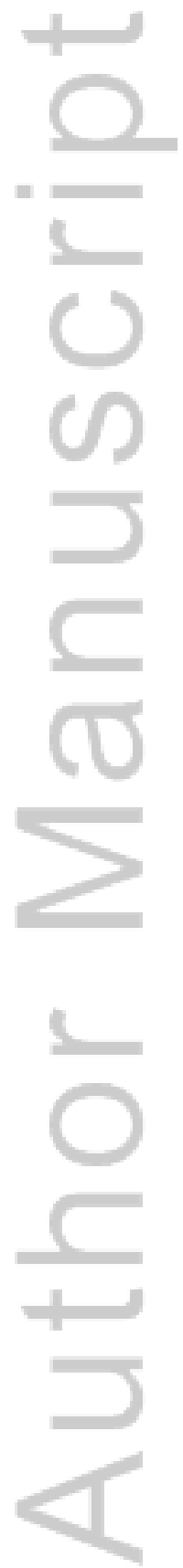

This article is protected by copyright. All rights reserved. 


\section{Introduction and Aims}

The young adult years are a critical developmental period marked by important transitions to adult roles [1,2] and a time when cannabis use generally peaks [3-5]. While definitions vary in relation to the point at which young adulthood may begin and end, there is generally consensus that the period includes the early 20s [6]. Experimentation with cannabis use is characteristic of the years leading into young adulthood [7-9]. A minority of young adults persist with cannabis use [10,11] and may experience a range of harms [12,13], while less entrenched users typically 'mature out' of use [7-9,14]. This raises questions about the extent to which the status of cannabis use in young adulthood is associated with subsequent adverse outcomes. While it is intuitively appealing to think that the risk of harm diminishes after quitting, research findings are conflicting. Prospective studies of adolescents in treatment have found that cannabis abstinence may improve interpersonal, occupational, and educational functioning $[15,16]$. Similarly, community-based studies which have examined various cannabis use trajectories suggest that patterns of declining use from adolescence to young adulthood are associated with lower delinquency and other substance use and greater well-being compared to escalating or chronic use [17]. The uptake of other illicit drugs has also been found to be lower in those who have quit cannabis than in occasional users [18]. In contrast, some studies have found that reducing cannabis use from daily to occasional use did not improve school attendance [15], or that alcohol use and lower school grades were more common in adolescents whose frequency of cannabis use had decreased than in adolescents whose frequency of cannabis use was consistently low [19]. Further, studies in older adults suggest that, over time (mean of 20 years), former cannabis users and non-users did not differ 
in current socio-demographic characteristics, substance use, healthcare utilisation or quality of life [20].

Evidence of any potential benefit associated with ceasing cannabis use is equivocal, and questions remain about whether young adult former users fare better than their age counterparts who use the drug infrequently. We address these issues using data from two waves of the young adult cohort of the PATH Through Life Study (PATH); being undertaken by the Centre for Research on Ageing, Health and Well-being at the Australian National University.

This study extends earlier work on the predictors of cannabis use in young adulthood [21]. Occasional cannabis use was the reference category which is an approach few have used [18]. This approach has the advantage that the normative, or most common, pattern of current cannabis use [5] is the comparison group. It is arguably more meaningful to compare extremes of use (i.e. former use and regular use) to the normative pattern as it provides important information about the outcomes associated with different levels of cannabis use.

The aim of the study was twofold: first, to investigate the association between cannabis use status at age 23 years and substance use and mental health outcomes at age 27 years, using occasional users as the reference group; and second, to adjust the associations reported for a wide range of potential confounding factors.

\section{Design and Methods}

Sample 
Data were analysed from two waves (wave one (surveyed 1999/2000), mean age 23 years, range 20-26, SD 1.51; wave two (surveyed 2003/2004), mean age 27 years, range 24-30, SD 1.50) of the 20+ year cohort from PATH, a community-based longitudinal survey of people randomly drawn from the electoral roll of the Australian Capital Territory and nearby Queanbeyan, New South Wales [22]. The design and methodology of PATH have been reported in detail previously [22]. Briefly, PATH is a comprehensive survey of the influence of lifestyle and social factors on health. The cohort is studied every four years. The main questionnaire is self-complete. Participation was voluntary and without remuneration. Of the 2404 participants originally enrolled in the PATH 20+ cohort, 15 cases were missing data on lifetime cannabis use and were excluded, leaving 2389. A further 707 cases were excluded as they reported never having used cannabis; non-users were excluded to allow age of first cannabis use to be included as a potential confounding factor in the analysis. The remaining 1682 cases reported lifetime cannabis use. Of these, 190 (11.2\%) were lost to follow-up. Among the 1492 remaining cases, 82 (5.5\%) were missing at least one value on the variables of interest and were also excluded. The study was based on 1410 lifetime cannabis users with complete data.

\section{Measures}

Cannabis use status at age 23 years. Based on age 23 assessment of lifetime cannabis use (yes or no) and frequency of past 12 months cannabis use (possible response categories were once a week or more, once a month, every one to four months, once or twice a year, less often), a three-level variable was created. Individuals were classified as: (i) former users 
(lifetime cannabis use but no use in the past 12 months); (ii) occasional users (cannabis use once a month or less in the past 12 months); and (iii) regular users (weekly or more frequent cannabis use in the past 12 months).

Outcomes at age 27 years. Based on frequency of alcohol use assessed with the Alcohol Use Disorders Identification Test (AUDIT) [23], individuals were classified as drinking alcohol $4+$ times a week or $<4$ times a week. Current tobacco (cigarette) use (yes or no) was assessed. Individuals were classified as recent cannabis users (past 12 months cannabis use) or non-recent cannabis users (no cannabis use in the past 12 months). A twoitem screen for substance use problems [24,25] was used as a proxy measure for cannabis dependence symptoms (in the past 12 months have you ever used cannabis more than you meant to; in the past 12 months have you ever felt you wanted or needed to cut down on your cannabis use). One or more affirmative responses were regarded as a positive screen [24,25]. No affirmative response was regarded as a negative screen for cannabis dependence symptoms. More than $80 \%$ of those with drug problems are recognised by the two-item screen $[24,25]$. As only past 12 months cannabis users were asked these items, former users were coded as having no cannabis dependence symptoms. Individuals were classified as recent users (past 12 months use) or non-recent users (includes never users) of other illicit drugs based on responses to individual items which asked about past 12 months use of ecstasy and amphetamines (these items were only included in the PATH survey from wave two). Mental health impairment was assessed using the 12-item Short Form Health Survey [26]. The survey assesses past month symptoms related to depressive/anxiety disorders and functional impairment due to mental health problems. A score of 42 or below on the mental 
health subscale indicated impaired mental health, where symptoms of depression could be expected [27]. The survey has demonstrated validity [28] and this cut point has been used previously in a large Australian community study [29].

Background factors and other measures at age 23 years. Background factors assessed at age 23 years included gender (male or female), ethnicity (Caucasian or non-Caucasian), parental divorce or separation during childhood (yes or no), secondary schooling (completed or not completed), employment (employed full-time/part-time or unemployed) relationship status (single or de-facto or married); having children (yes or no); and age of first cannabis use (dichotomised to $<16$ years and $\geq 16$ years). Frequency of alcohol use, current tobacco use, cannabis dependence symptoms, and mental health impairment were also assessed, categorised as described above for age 27 years.

\section{Statistical analyses}

First, cross-sectional analyses were conducted using multinomial logistic regression to estimate the association between cannabis use status (dependent variable) and background and other factors (predictor variables), assessed at age 23 years. Previous research suggested that these factors might be correlated with both cannabis use and adverse outcomes and they were included as covariates in the subsequent prospective analyses. Second, the prospective analyses used binary logistic regression to estimate the association between cannabis use status at age 23 years and the outcomes assessed at age 27 years. These analyses included one bivariable logistic regression model (Model 1) and a multivariable logistic regression model 
(Model 2) which adjusted for: gender, ethnicity, parental divorce in childhood, secondary schooling, employment, relationship status, having children, age of first cannabis use, frequency of alcohol use, current tobacco use, and mental health impairment (all assessed at age 23 years). Other illicit drug use at age 23 years could not be included as a potential confounding factor as these data were not collected. Associations were expressed as the odds ratio $(\mathrm{OR})$ and $95 \%$ confidence interval $(\mathrm{CI})$. The multivariable model was examined for collinearity.

Data were analysed using IBM SPSS version 18. In reporting results, mean ages were used to distinguish wave one (mean age 23 years) from wave two (mean age 27 years). The research protocol was approved by the Human Research Ethics Committee of UNSW Australia [2008-7-71].

\section{Results}

Of the 1410 lifetime cannabis users at age 23 years, just over half $(53 \%, n=750)$ were past users, having not used cannabis in the previous 12 months. Approximately one-third (34\%, $\mathrm{n}=483)$ were occasional users and $13 \%(\mathrm{n}=177)$ used cannabis regularly (weekly or more often).

Associations between cannabis use status, background factors, and other measures, at age 23 years

This article is protected by copyright. All rights reserved. 
The associations between cannabis use status, background factors and other measures, at age 23 years, are reported in Table 1. Compared to occasional cannabis users at age 23 years, former users at that age were more likely to be female, in a de-facto relationship or married, and have children, and less likely to currently smoke tobacco, and have impaired mental health. Regular use of the drug at age 23 years was more common in males, secondary school non-completers, early initiators of cannabis use, frequent alcohol drinkers, current tobacco smokers, and people with impaired mental health.

Associations between cannabis use status at age 23 years and outcomes at age 27 years

The associations between cannabis use status at age 23 years and outcomes at age 27 years, in unadjusted and adjusted models, are reported in Table 2. In bivariable regression models (Model 1, unadjusted) there were large and statistically significant associations between cannabis use status at age 23 years and all outcomes at age 27 years. Compared to occasional cannabis users at age 23 years, former users at that age had odds of: (i) tobacco use at age 27 years that were $33 \%$ lower; (ii) recent cannabis use at age 27 years that were $78 \%$ lower; (iii) cannabis dependence symptoms at age 27 years that were $77 \%$ lower; (iv) other illicit drug use at age 27 years that were $71 \%$ lower; and (v) mental health impairment at age 27 years that were $29 \%$ lower. In contrast, compared to occasional cannabis users at age 23 years, regular cannabis users at that age had odds of: (i) frequent alcohol use at age 27 years that were two times greater; (ii) tobacco use at age 27 years that were about four times greater; (iii) recent cannabis use at age 27 years that were 12 times greater; (iv) cannabis dependence 
symptoms at age 27 years that were 13 times greater; and (v) other illicit drug use at age 27 years that were three times greater.

Multivariable regression models were used to examine whether the associations observed were due to the effects of potential confounding factors (Model 2, adjusted). With control for confounding: (i) the magnitude of the above associations diminished and most remained statistically significant $(P<0.05$ to $P<0.001)$; (ii) for both former and regular cannabis use at age 23 years, the association with tobacco use at age 27 years was negligible in size and no longer statistically significant; and (iii) dose-response type associations were observed between all illicit drug use outcomes at age 27 years and cannabis use status at age 23 years. For example, there was an increase in the OR for recent cannabis use at age 27 years with progressively more frequent cannabis use at age 23 years (i.e. former use, $\mathrm{OR}=0.24$; occasional use, $\mathrm{OR}=1$; regular use, $\mathrm{OR}=9.50$ ). A similar pattern was observed for cannabis dependence symptoms and other illicit drug use. In other words, occasional cannabis users were intermediate in risk level between former and regular users for these outcomes. There was no evidence of collinearity in the adjusted model (Model 2) for each outcome.

\section{Discussion}

This study examined the associations between cannabis use status in young adulthood and subsequent substance use outcomes and mental health among a sample of individuals aged in their 20s. Compared to previous studies in this general area, this study had a number of 
advantages. First, findings were drawn from a large population-based sample of young adults that were followed prospectively. Second, the study examined the substance use and mental health outcomes associated with cannabis use status during young adulthood, a period not commonly investigated. Third, the extremes of cannabis use were compared to occasional use, the normative or most common pattern of current cannabis use.

We note three main findings from the analyses: (i) compared to occasional cannabis users at age 23 years, former users had significantly decreased odds at age 27 years of tobacco use, illicit drug use (cannabis and other illicit drugs) and mental health impairment; (ii) regular users had significantly increased odds at age 27 years of frequent alcohol use, current tobacco use, recent cannabis use, cannabis dependence symptoms, and other illicit drug use; and (iii) the observed associations were resilient to control for the range of potential confounding factors assessed, except in the case of tobacco use at age 27 years where adjustment reduced the significance of the association.

With control for potential observed confounders, former cannabis users had odds of subsequent mental health impairment that were about $25 \%$ lower than occasional users, consistent with studies that have shown that patterns of declining cannabis use are associated with improvements in well-being compared to chronic or escalating use [17]. Former cannabis users also had reduced odds of other illicit drug use compared to current cannabis users; a finding which supports earlier research [18]. Not surprisingly, young adult former users had substantially (73-76\%) decreased odds of subsequent cannabis use and dependence symptoms compared to occasional users. These findings strengthen evidence of the important role prior cannabis use has in current patterns of cannabis and other illicit drug use $[8,30]$. 
Our finding that regular cannabis use in young adulthood was associated with increased odds of subsequent cannabis use, cannabis dependence symptoms, and other illicit drug use compared to occasional use is consistent with findings from existing studies of adolescent cannabis users [18,31-34]. Taken together, this suggests that the link between heavy cannabis use and later cannabis dependence and illicit substance use extends well beyond adolescence and into young adulthood. Specifically, we found that the odds of these outcomes were between three to ten times greater for young adult regular users than occasional users even after adjustment. Young adult regular cannabis users were also at increased risk of more frequent alcohol use. Compared to occasional cannabis use at age 23 years, weekly or more frequent cannabis use predicted a doubling of the odds for more frequent alcohol use at age 27 years. The effects diminished slightly after adjustment for a range of potential confounding factors that included current alcohol and tobacco use. These findings are broadly consistent with studies among adolescents [18], suggesting that weekly or more frequent cannabis use in early young adulthood may be an independent predictor of more frequent alcohol use. However, other research has found a tendency for heavy cannabis users to continue predominantly with only cannabis use [35].

We found that regular cannabis use in young adulthood was not significantly associated with subsequent mental health impairment compared to occasional use. Previous research suggests that cannabis use may be associated with mental health problems such as depression [36] and psychosis [37], particularly in vulnerable individuals. In the present study, a broad measure of mental health (i.e. SF-12) was used, rather than a diagnostic measure, which may partly account for the observed result. We also found that in the adjusted 
model, tobacco use at age 27 years did not remain significantly associated with cannabis use status at age 23 years. Further examination of this model by including each covariate progressively revealed that prior cigarette use largely accounted for the association, particularly among former cannabis users. This is consistent with earlier research that found that adolescent tobacco use accounted almost entirely for the association between nicotine dependence at age 24 years and adolescent cannabis use [38].

Studies such as ours do not allow for causal inferences to be made and are limited in their capacity to shed light on the various underlying mechanisms of the relationships observed. However, some research has suggested that cannabis may modify responsiveness to drugs at a biological level [39]; alternatively, the association between cannabis use and other drug use may be explained by common genetic or shared environmental factors which impact on the propensity for the use of these substances [40,41]. Normative social role transitions and new responsibilities, such as marriage and parenthood, are thought to contribute to declining patterns of cannabis and other substance use in young adulthood $[2,7,42]$. However, our results suggest that even after taking relationship status and parenthood into account, cannabis use in young adulthood remains associated with subsequent use of alcohol and illicit drugs.

Several possible explanations may underpin the association between cannabis use and mental health in young adulthood: it is biologically plausible as cannabis use can have multiple effects on brain biochemistry [43,44]; alternatively, common individual, social and contextual factors may influence vulnerability to both cannabis use and mental health problems [45]. It is also possible that former cannabis use may contribute to a decreased risk 
of mental health impairment indirectly through increased well-being [17] and improved psychosocial adjustment.

\section{Limitations}

This study has some limitations. First, of the original sample of lifetime cannabis users $(\mathrm{N}=1682), 11 \%(\mathrm{~N}=190)$ were lost to follow-up and 5\% (N=82) were missing at least one value on the variables of interest, leaving $84 \%(\mathrm{~N}=1410)$ of the original sample in the complete cases analysis. Further analysis of those excluded and included revealed small but statistically detectable tendencies for the sample of complete cases to under-represent males and those who were less educated. Although this suggests some small non-random sample loss, it is unlikely that these losses would have materially influenced the results or representativeness of the sample. Second, common to all longitudinal studies is the issue that behaviours during the period between assessments are not measured (and, therefore, not known). This study examined cannabis status at age 23 years. Former cannabis users had not used for at least 12 months, however the specific timing of cessation and pattern of cannabis use prior to age 23 years cannot be determined from the available data. Third, it was not possible to include other illicit drug use at age 23 years as a covariate as these data were not collected in wave one of the PATH 20+ survey. It is therefore plausible that some of the effects observed may be partly explained by the prior use of other illicit drugs, had this variable been included. Fourth, data were based on self-reports which raises the possibility of under- or over-reporting. However, self-report has been shown to be an appropriate way to collect information about population drug use and other behaviours [46]. Fifth, some caution 
is necessary when generalising the findings to the Australian population and to other populations of young adults (e.g. disengaged young adults - who may have higher rates of cannabis use - are under-represented in the electoral roll). Individuals aged 20-29 years on the electoral roll were sent letters to establish who was aged 20-24 years (the target age group for the 20+ year PATH cohort). Twenty-four percent of the 20-29 year olds sent letters were not traceable or had moved from the region and it was not possible to determine if they were in the target age group. Therefore, we were not able to ascertain whether there were differences between those who were not traceable or had moved (in the target age group) and those who participated. If those people who did not participate in the survey had poorer functioning, on average, than those people who participated, the results reported are likely to be conservative. The response rate for wave one was $58.6 \%$; which represents the proportion of 20-24 year olds contacted that participated. The response rate for wave two was $89.0 \%$. Rates of cannabis use in young people in Australia are similar to those in other high-income countries [47] which supports the generalizability of findings to those settings. Nevertheless, the social and legislative context of cannabis use can vary between regions and remains an important consideration in the generalisation and replication of findings.

\section{Conclusions}

Notwithstanding these reservations, study findings support the conclusion that young adult former cannabis users fare better than their age counterparts who are infrequent users in terms of subsequent illicit drug use and mental health impairment. While early intervention remains important to prevent regular cannabis use and the associated harms [31], it is an important 
public health message that experimentation with cannabis use in the years leading into young adulthood may not necessarily determine an immutable pathway to mental health problems and illicit substance use.

\section{Acknowledgments}

We thank the study participants, PATH Interviewers, Patricia Jacomb, Karen Maxwell, and Tony Jorm. We would also like to acknowledge the contribution of Kaaren Anstey. Wave 1 and Wave 2 of the PATH Through Life Study were funded by National Health and Medical Research Council Grants (NHMRC Program Grant No. 229936, 179839, 179805). This work was supported by a scholarship provided by the National Drug and Alcohol Research Centre, UNSW Australia. DMH was supported by a vice-chancellor's postdoctoral fellowship from UNSW Australia.The National Drug and Alcohol Research Centre at UNSW Australia is supported by funding from the Australian Government. We also wish to acknowledge the Cannabis Cohorts Research Consortium.

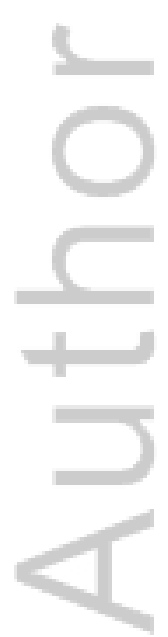

This article is protected by copyright. All rights reserved. 


\section{References}

[1] Arnett J. A theory of development from the late teens through the twenties. Am Psychol 2000;55:469-80.

[2] Bachman J, O'Malley P, Schulenberg J, et al. The decline of substance use in young adulthood: Changes in social activities, roles, and beliefs. Galambos N, BuschRossnagel N, editors. Mahwah, New Jersey: Lawrence Erlbaum Associates, Publishers; 2002.

[3] Substance Abuse and Mental Health Services Administration. Behavioural trends in the United States: Results from the 2014 National Survey on Drug Use and Health. Rockville, MD: Centre for Behavioural Health Statistics and Quality, 2015.

[4] European Monitoring Centre for Drugs and Drug Addiction. European Drug Report. Spain: EMCDDA, 2016.

[5] Australian Institute of Health and Welfare. National Drug Strategy Household Survey. Canberra: AIHW, 2016.

[6] Schulenberg J, Sameroff A, Cicchetti D. The transition to adulthood as a critical juncture in the course of psychopathology and mental health. Dev Psychopathol 2004;16:799-806.

[7] Kandel D, Logan J. Patterns of drug use from adolecence to young adulthood:1. Periods of risk for initiation, continued use, and discontinuation. Am J Public Health 1984;74:660-6.

[8] Raveis V, Kandel D. Changes in drug behaviour from the middle to the late twenties: Initiation, persistence, and cessation of use. Am J Public Health 1987;77:607-11. 
[9] Chen K, Kandel D. The natural history of drug use from adolescence to the midthirties in a general population sample. Am J Public Health 1995;85:41-7.

[10] Farmer R, Kosty D, Seeley J, et al. Natural course of cannabis use disorders. Psychol Methods 2015;45:63-72.

[11] Swift W, Coffey C, Carlin JB, Degenhardt L, Patton GC.. Adolescent cannabis users at 24 years: trajectories to regular weekly use and dependence in young adulthood. Addiction 2008;103:1361-70.

[12] Hall W. Reducing the harms caused by cannabis use: The policy debate in Australia. Drug Alcohol Depend 2001;62:163-74.

[13] Danielsson AK, Falkstedt D, Hemmingsson T, Allebeck P, Agardh E. Cannabis use among Swedish men in adolescence and the risk of adverse life course outcomes: results from a 20 year-follow-up study. Addiction 2015;110:1794-802.

[14] von Sydow K, Lieb R, Pfister H, Höfler M, Sonntag H, Wittchen HU. The natural course of cannabis use, abuse and dependence over four years: a longitudinal community study of adolescents and young adults. Drug Alcohol Depend 2001;64:347-61.

[15] Engberg J, Morral A. Reducing substance use improves adolescents' school attendence. Addiction 2006;101:1741-51.

[16] Griffin BA, Ramchand R, Edelen MO, McCaffrey DF, Morral AR. Associations between abstinence in adolescence and economic and educational outcomes seven years later among high-risk youth. Drug Alcohol Depend 2011;113:118-24. 
[17] Schulenberg JE, Merline AC, Johnston LD, O'Malley PM, Bachman JG, Laetz VB. Trajectories of marijuana use during the transition to adulthood: the big picture based on national panel data. J Drug Issues 2005;35(2):255-79.

[18] Swift W, Coffey C, Degenhardt L, Carlin JB, Romaniuk H, Patton GC. Cannabis and progression to other substance use in young adults: Findings from a 13-year prospective population-based study. J Epidemiol Community Health 2012;66:e26.

[19] Windle M, Wiesner M. Trajectories of marijuana use from adolescence to young adulthood: predictors and outcomes. Dev Psychopathol 2004;16:1007-27.

[20] Eisen SA, Chantarujikapong S, Xian H, et al. Does marijuana use have residual adverse effects on self-reported health measures, socio-demographics and quality of life? A monozygotic co-twin control study in men. Addiction 2002;97:1137-44.

[21] Silins E, Hutchinson D, Swift W, Slade T, Toson B, Rodgers B. Factors associated with variability and stability of cannabis use in young adulthood. Drug Alcohol Depend 2013;133:452-8.

[22] Rodgers B1, Windsor TD, Anstey KJ, Dear KB, F Jorm A, Christensen H. Non-linear relationships between cognitive function and alcohol consumption in young, middleaged and older adults: the PATH Through Life Project. Addiction 2005;100:1280-90.

[23] World Health Organization. The Alcohol Use Disorders Identification Test. Guidelines for use in primary care. Second edition. Geneva: World Health Organization, Department of Mental Health and Substance Dependence; 2001.

[24] Brown RL, Leonard T, Saunders LA, Papasouliotis O. A two-item conjoint screen for alcohol and other drug problems. J Am Board Fam Pract 2001;14:95-106.

This article is protected by copyright. All rights reserved. 
[25] Brown RL, Leonard T, Saunders LA, Papasouliotis O. A two-item screening test for alcohol and other drug problems. J Fam Pract 1997;44:151-61.

[26] Ware J, Kosinski M, Kellar S. A 12-item Short-Form health survey. Construction of scales and preliminary tests of reliability and validity. Med Care 1996;34:220-33.

[27] Ware J, Kosinski M, Kellar S. SF-36 Physical and mental health summary scales: a user's manual. Boston, MA: New England Medical Centre; 1997.

[28] Sanderson K, Andrews G. The SF-12 in the Australian population: cross-validation of item selection. Aust N Z J Public Health 2002;26:343-5.

[29] Baum F, Bush R, Modra C, et al. Epidemiology of participation: an Australian community study. J Epidemiol Community Health 2000;54:414-23.

[30] Aitken SS, DeSantis J, Harford TC, Cases MF. Marijuana use among adults: A longitudinal study of current and former users. J Subst Abuse 2000;12:213-26.

[31] Silins E, Horwood L, Patton G, et al. Young adult sequelae of adolescent cannabis use: an integrative analysis. Lancet Psychiatry 2014;1:286-93.

[32] Fergusson D, Boden J, Horwood J. The developmental antecedents of illicit drug use: Evidence from a 25-year longitudinal study. Drug Alcohol Depend 2008;96:165-77.

[33] Perkonigg A, Goodwin R, Fielder A, et al. The natural course of cannabis use, abuse and dependence during the first decades of life. Addiction 2008;103:439-49.

[34] Degenhardt L, Dierker L, Chui W, et al. Evaluating the drug use 'gateway' theory using cross-national data: Consistency and associations of the order of initiation of drug use among participants in the WHO World Mental Health Survey. Drug Alcohol Depend 2010;108:84-97. 
[35] Patton G, Coffey C, Lynsky M, et al. Trajectories of adolescent alcohol and cannabis use into young adulthood. Addiction 2007;102:607-15.

[36] Horwood J, Fergusson D, Coffey C, et al. Cannabis and depression: An integrative data analysis of four Australasian cohorts. Drug Alcohol Depend 2012;126:369-78.

[37] McLaren J, Silins E, Hutchinson D, et al. Assessing evidence for a causal link between cannabis and psychosis: A review of cohort studies. Int J Drug Policy 2010;21:10-9.

[38] Degenhardt L, Coffey C, Carlin JB, Swift W, Moore E, Patton GC. Outcomes of occasional cannabis use in adolescence: 10 year follow-up study in Victoria, Australia. Br J Psychiatry 2010;196:290-5.

[39] Schenk S. Sensitization as a process underlying the progression of drug use via gateway drugs. In: Kandel D, editor. Stages and Pathways of Drug Involvement:

Explaining the gateway hypothesis. New York: Cambridge University Press; 2002. p. 318-36.

[40] Lynskey M, Vink J, Boomsma D. Early onset cannabis use and progression to other drug use in a sample of Dutch twins. Behav Genet 2006;36:195-200.

[41] Agrawal A, Neale MC, Prescott CA, Kendler KS. A twin study of early cannabis use and subsequent use and abuse/dependence of other illicit drugs. Psychol Med 2004;34:1227-37.

[42] Kandel DB, Davies M, Karus D, Yamaguchi K. The consequences in young adulthood of adolescent drug involvement. Arch Gen Psychiatry 1986;43:746-54.

This article is protected by copyright. All rights reserved. 
[43] Squeglia L, Jacobus J, Tapert S. The influence of substance use on adolescent brain development. Clin EEG Neurosci 2009;40:31-8.

[44] Lisdahl KM, Gilbart ER, Wright NE, Shollenbarger S. Dare to delay? The impacts of adolescent alcohol and marijuana use onset on cognition, brain structure, and function. Front Psychiatry 2013;4:25-43.

[45] Degenhardt L, Hall W, Lynskey M. Exploring the association between cannabis use and depression. Addiction 2003;98:1493-504.

[46] Darke S. Self-report among injecting drug users: a review. Drug Alcohol Depend 1998;51:253-63.

[47] UNICEF Office of Research. Child well-being in rich countries: a comparative overview. Florence: UNICEF Office of Research, 2013.

This article is protected by copyright. All rights reserved. 
Table 1. Association of background factors and other measures with cannabis use status at age 23 years in 1410 participants

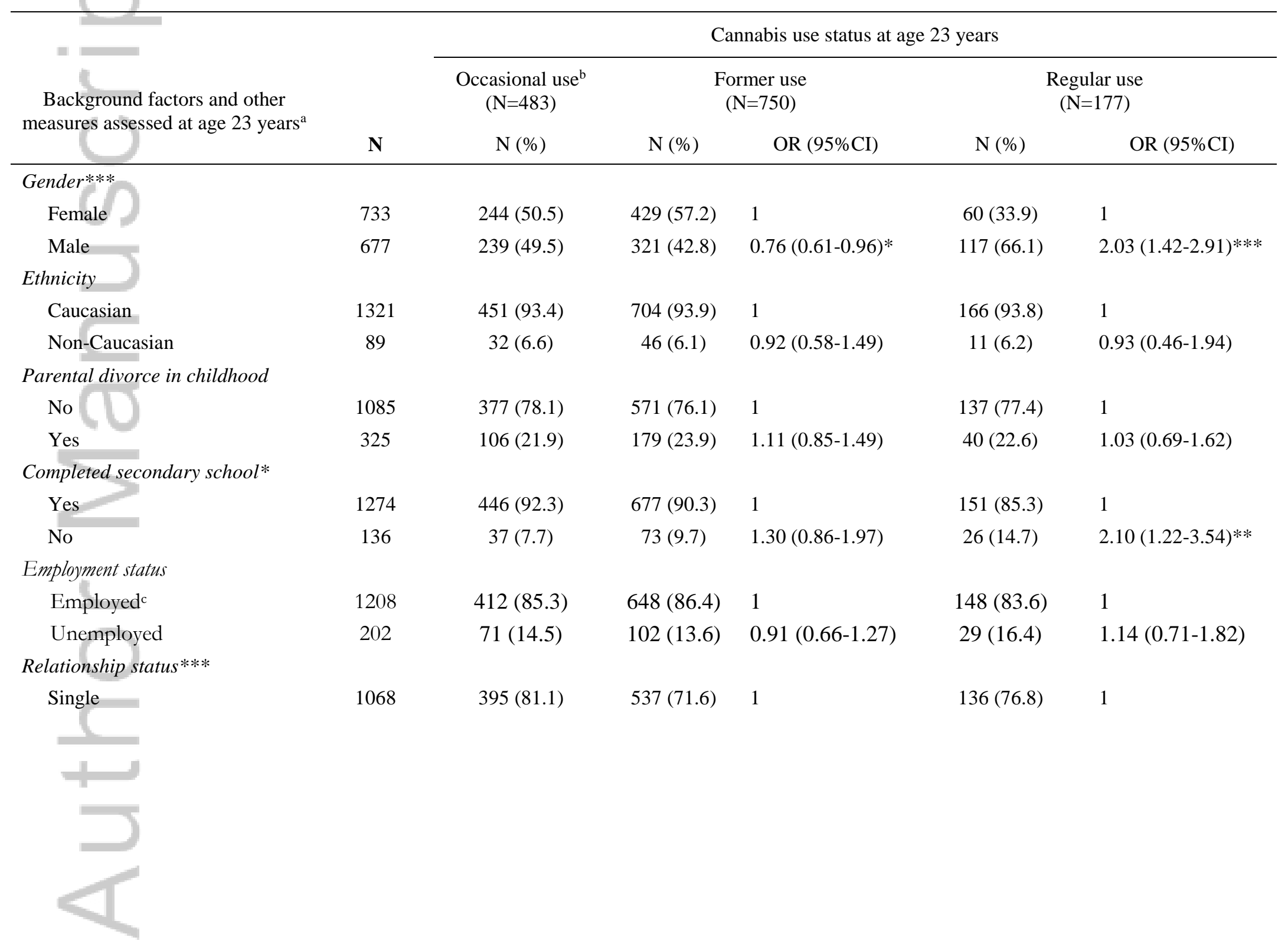

This article is protected by copyright. All rights reserved. 


\begin{tabular}{|c|c|c|c|c|c|c|}
\hline De facto & 234 & $67(13.9)$ & $133(17.7)$ & $1.46(1.06-2.01)^{*}$ & $34(19.2)$ & $1.47(0.93-2.33)$ \\
\hline Married & 108 & $21(4.3)$ & $80(10.7)$ & $\begin{array}{l}2.80(1.70- \\
4.61)^{* * *}\end{array}$ & $7(4.0)$ & $0.97(0.40-2.33)$ \\
\hline \multicolumn{7}{|l|}{ Have children } \\
\hline No & 1256 & $443(91.7)$ & $655(87.3)$ & 1 & $158(89.3)$ & 1 \\
\hline Yes & 154 & $40(8.3)$ & $95(12.7)$ & $1.61(1.09-2.37)^{*}$ & $19(10.7)$ & $1.33(0.75-2.37)$ \\
\hline \multicolumn{7}{|c|}{ Age of first cannabis use **** $^{*}$} \\
\hline$\geq 16$ years & 999 & $353(73.1)$ & $552(73.6)$ & 1 & $94(53.1)$ & 1 \\
\hline$<16$ years & 411 & $130(26.9)$ & $198(26.4)$ & $0.97(0.75-1.28)$ & $83(46.9)$ & $2.37(1.73-3.38)^{* * *}$ \\
\hline \multicolumn{7}{|c|}{ Frequency of alcohol use *** $^{*}$} \\
\hline$<4$ drinks per week & 1292 & $445(92.1)$ & $697(93.9)$ & 1 & $150(84.7)$ & 1 \\
\hline 4+ drinks per week & 118 & $38(7.9)$ & $53(7.1)$ & $0.89(0.58-1.44)$ & $27(15.3)$ & $2.04(1.19-3.63)^{* *}$ \\
\hline \multicolumn{7}{|l|}{ Current tobacco use $e^{* * *}$} \\
\hline No & 829 & $278(57.6)$ & $510(68.0)$ & 1 & $41(23.2)$ & 1 \\
\hline Yes & 581 & $205(42.4)$ & $240(32.0)$ & $\begin{array}{l}0.64(0.50- \\
0.81)^{* * * *}\end{array}$ & $136(76.8)$ & $4.50(3.01-6.72)^{* * *}$ \\
\hline \multicolumn{7}{|c|}{ Cannabis dependence symptoms*** } \\
\hline No & 1141 & $368(76.2)$ & $750(100)$ & $-^{\mathrm{d}}$ & $23(13.0)$ & $-^{\mathrm{d}}$ \\
\hline Yes & 269 & $115(23.8)$ & 0 & - & $154(87.0)$ & - \\
\hline \multicolumn{7}{|c|}{ Impaired mental health ${ }^{* * *}$} \\
\hline No & 1009 & $338(70.0)$ & $576(76.8)$ & 1 & $95(53.7)$ & 1 \\
\hline Yes & 401 & $145(30.0)$ & $174(23.2)$ & $\begin{array}{l}0.70(0.54- \\
0.91)^{* * *} \\
\end{array}$ & $82(46.3)$ & $2.02(1.39-2.91)^{* * *}$ \\
\hline
\end{tabular}

This article is protected by copyright. All rights reserved. 
${ }^{*} P<0.05,{ }^{* *} P<0.01, * * * P<0.001$; OR, odds ratio; CI, confidence interval. ${ }^{\text {a }}$ Asterisk indicates significance level of univariable likelihood ratio chi-square test; ${ }^{\mathrm{b}}$ Reference group; ${ }^{\mathrm{c}}$ Full-time/part-time; ${ }^{\mathrm{d}}$ Not computable as only current cannabis users were asked about cannabis dependence symptoms; Note: other illicit drug use at age 23 years not included as these data were not collected.

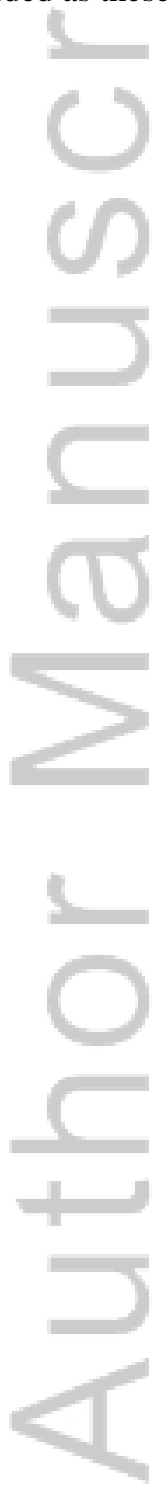

This article is protected by copyright. All rights reserved. 
Table 2. Associations between cannabis use status at age 23 years and outcomes at age 27 years, adjusted for potential confounding factors

\begin{tabular}{|c|c|c|c|c|c|c|}
\hline \multirow{2}{*}{$\begin{array}{c}\text { Cannabis use status at age } \\
23 \text { years }\end{array}$} & \multicolumn{6}{|c|}{ Substance use and mental health outcome at age 27 years } \\
\hline & $\begin{array}{l}\text { Frequent alcohol } \\
\text { use } \\
(\mathrm{N}=225)\end{array}$ & $\begin{array}{l}\text { Current tobacco use } \\
\qquad(\mathrm{N}=511)\end{array}$ & $\begin{array}{l}\text { Recent cannabis use } \\
\qquad(\mathrm{N}=502)\end{array}$ & $\begin{array}{c}\text { Cannabis dependence } \\
\text { symptoms } \\
(\mathrm{N}=202)\end{array}$ & $\begin{array}{l}\text { Other illicit drug use } \\
\qquad(\mathrm{N}=382)\end{array}$ & $\begin{array}{l}\text { Mental health } \\
\text { impairment } \\
(\mathrm{N}=381)\end{array}$ \\
\hline \multicolumn{7}{|l|}{ Occasional use $(N=483)$} \\
\hline $\mathrm{N}(\%)^{\mathrm{a}}$ & $73(15.1)$ & $179(37.1)$ & $223(46.2)$ & $62(12.8)$ & $170(35.2)$ & $144(29.8)$ \\
\hline OR & 1 & 1 & 1 & 1 & 1 & 1 \\
\hline \multicolumn{7}{|l|}{ Former use $(N=750)$} \\
\hline $\mathrm{N}(\%)$ & $100(13.3)$ & $211(28.1)$ & $118(15.7)$ & $25(3.3)$ & $103(13.7)$ & $174(23.2)$ \\
\hline Model 1, ${ }^{\mathrm{b}}$ OR (95\% CI) & $0.86(0.62-1.20)$ & $0.67(0.52-0.85)^{* *}$ & $0.22(0.17-0.28)^{* * *}$ & $0.23(0.15-0.38)^{* * *}$ & $0.29(0.22-0.39)^{* * *}$ & $0.71(0.55-0.92)^{*}$ \\
\hline Model 2, ${ }^{\mathrm{c}}$ OR $(95 \% \mathrm{CI})$ & $0.97(0.67-1.34)$ & $0.81(0.58-1.12)$ & $0.24(0.18-0.31)^{* * *}$ & $0.27(0.17-0.44)^{* * *}$ & $0.32(0.24-0.43)^{* * *}$ & $0.76(0.58-0.99)^{*}$ \\
\hline \multicolumn{7}{|l|}{ Regular use $(N=177)$} \\
\hline $\mathrm{N}(\%)$ & $52(29.3)$ & $121(68.4)$ & $161(90.9)$ & $115(64.9)$ & $109(61.6)$ & $63(35.6)$ \\
\hline Model 1, ${ }^{\mathrm{b}}$ OR $(95 \% \mathrm{CI})$ & $2.34(1.55-3.51)^{* * *}$ & $3.67(2.54-5.30)^{* * *}$ & $11.73(6.81-20.21)^{* * *}$ & $12.60(8.38-18.94)^{* * *}$ & $2.95(2.07-4.21)^{* * *}$ & $1.30(0.90-1.87)$ \\
\hline Model 2, ${ }^{\mathrm{c}}$ OR $(95 \% \mathrm{CI})$ & $1.65(1.03-2.62) *$ & $1.62(1.01-2.63)$ & $9.50(5.41-16.68)^{* * *}$ & $9.53(6.14-14.81)^{* * *}$ & $2.54(1.73-3.74)^{* * *}$ & $0.99(0.67-1.49)$ \\
\hline
\end{tabular}

$* \mathrm{P}<0.05$, ** $\mathrm{P}<0.01, * * * \mathrm{P}<0.001$; OR, odds ratio; CI, confidence interval. ${ }^{\mathrm{a}}$ Percentage of group by cannabis use status with each outcome at age 27 years. ${ }^{\mathrm{b}}$ Model 1 : OR

from bivariable logistic regression model. ${ }^{\mathrm{c}}$ Model 2: OR from multivariable logistic regression model, adjusted for the following potential confounding factors assessed at age 23 years: gender, ethnicity, parental divorce in childhood, secondary schooling, employment, relationship status, having children, age of first cannabis use, frequency of 
alcohol use, current tobacco use, and mental health impairment; Other illicit drug use at age 23 years was not included as a potential confounding factor as these data were not collected.

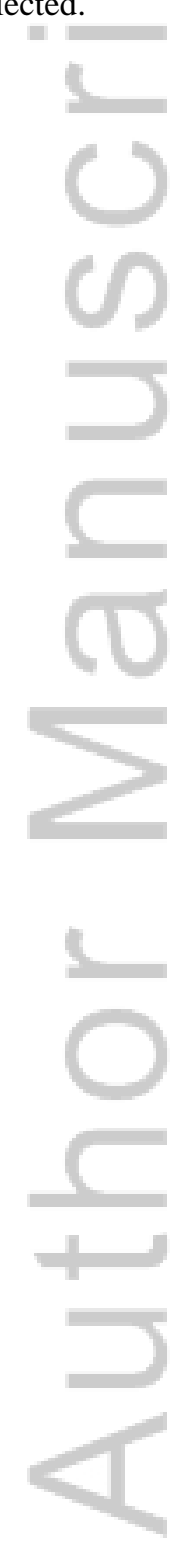

This article is protected by copyright. All rights reserved. 


\section{University Library}

\section{- M M N E R VA A gateway to Melbourne's research publications}

Minerva Access is the Institutional Repository of The University of Melbourne

Author/s:

Silins, E;Swift, W;Slade, T;Toson, B;Rodgers, B;Hutchinson, DM

Title:

A prospective study of the substance use and mental health outcomes of young adult former and current cannabis users

Date:

2017-09-01

Citation:

Silins, E., Swift, W., Slade, T., Toson, B., Rodgers, B. \& Hutchinson, D. M. (2017). A prospective study of the substance use and mental health outcomes of young adult former and current cannabis users. DRUG AND ALCOHOL REVIEW, 36 (5), pp.618-625. https:// doi.org/10.1111/dar. 12512.

Persistent Link:

http://hdl.handle.net/11343/292667 